\title{
Percepções de um professor pesquisador e de seus alunos e alunas sobre a Educação Física: uma pesquisa colaborativa
}

Daniel Teixeira Maldonado ${ }^{a, b *}$, Luana Tavares de Oliveira Alves ${ }^{a}$, Gabriel Neves Grassia ${ }^{a}$ Ronie Nery da Silva ${ }^{a}$, Luiz Sanches Netoc,d, Elisabete dos Santos Freire ${ }^{a}$

Palavras Chave:

Currículo;

Educação;

Docentes;

Estudantes.

\begin{abstract}
RESUMO
Os conhecimentos elaborados por professores de Educação Física têm sido valorizados, ainda que lentamente, por pesquisadores que reconhecem lacunas formativas e condições de trabalho que tornam improvável o envolvimento do professor com a pesquisa. Nesse sentido, nossos objetivos nesta pesquisa qualitativa colaborativa são: identificar as percepções dos estudantes sobre as aulas e discutir as percepções do professor tanto sobre as aulas quanto sobre as percepções dos alunos. Houve colaboração de um professor de Educação Física e 48 estudantes de uma escola pública municipal de São Paulo, que participaram por meio de questionário e entrevista. Os resultados apontam transformação na percepção do professor à medida que elabora conhecimentos sobre a sua prática pedagógica.
\end{abstract}

\section{Keywords:}

Curriculum;

Education;

Teacher;

Student.

\section{Palavras Chave:}

Curriculum;

Educación;

Docentes;

Estudiantes.

\begin{abstract}
Knowledge developed by Physical Education teachers has been valued, albeit slowly, by academic researchers who recognize educational gaps and working conditions that make it unlikely that the teacher becomes involved in researching. Our objectives in this qualitative collaborative research are: to identify the students' perceptions on their classes and to discuss the teacher's perceptions both on the classes and the students' perceptions. One Physical Education teacher collaborated and 48 students from a public municipal school at São Paulo participated through questionnaire and interview. The results point to a transformation in the teacher's perception as he elaborates knowledge on the pedagogical practice.
\end{abstract}

\begin{abstract}
RESUMEN
Los conocimientos elaborados por maestros de Educación Física han sido valorados por investigadores académicos que reconocen problemas formativos y condiciones de trabajo que hacen improbable la participación de maestros con la investigación. Nuestros objetivos en esta investigación cualitativa colaborativa son: identificar las percepciones de los estudiantes sobre las clases y discutir las percepciones del profesor, tanto sobre las clases cuanto las percepciones de los alumnos. Hubo colaboración de un profesor de Educación Física y 48 estudiantes de una escuela municipal de São Paulo participaron por medio de cuestionario y entrevista. Los resultados apuntan a la transformación en la percepción del profesor a medida que elabora conocimientos sobre su propia práctica pedagógica.
\end{abstract}

\footnotetext{
a Universidade São Judas, São Paulo, SP, Brasil.

${ }^{\mathrm{b}}$ Instituto Federal de São Paulo, São Paulo, SP, Brasil.

' Universidade Estadual Paulista - UNESP, SP, Brasil.

dUniversidade Federal do Ceará, no Instituto de Educação Física e Esportes, Fortaleza, CE, Brasil.
}

\author{
*Autor correspondente: \\ Daniel Teixeira Maldonado \\ E-mail: danieltmaldonado@yahoo.com.br
}




\section{INTRODUÇÃO}

Ainda que lentamente, é possivel perceber que os conhecimentos elaborados pelo professor no cotidiano escolar vêm sendo valorizados por pesquisadores que investigam o ensino da Educação Física (EF) na escola. Martins e Freire (2013) e Bins e Molina Neto (2017), por exemplo, apresentam estudos nos quais são analisadas as práticas pedagógicas implementadas por professores que elaboram conhecimento e, como tal, poderiam ilustrar a comparação que Stenhouse $(1980 ; 1991)$ faz entre um professor que age como pesquisador e um artista. Para Stenhouse, ao buscar as melhores formas de possibilitar a aprendizagem dos alunos, como fazem os participantes dos estudos anteriormente citados, o professor age de modo semelhante ao artista, utilizando os recursos disponíveis para elaborar sua criação (Fagundes, 2016). Assim, de forma crítica e sistemática, ele investiga o trabalho que realiza e, intencionalmente, tenta aprimorar sua arte, enquanto a exerce (Stenhouse, 1980).

Outros autores, como Okimura-Kerr et al. (2017) e Farias et al. (2017), também têm reconhecido e divulgado o conhecimento produzido por professores, no contexto da EF. Essas obras demonstram que, embora a cultura escolar, as lacunas na formação profissional e as condições materiais e estruturais de trabalho enfrentadas pelo professor tornem seu envolvimento com a pesquisa algo improvável (Cunha; Prado, 2007), alguns deles superam essas barreiras e investigam a sua própria prática.

É nesse contexto que as características da pesquisa realizada pelo professor têm sido analisadas. Cunha e Prado (2007) explicam que, por vezes, a legitimidade dessa forma de investigação tem sido questionada por alguns pesquisadores. Contrários a esta concepção, os autores argumentam que as pesquisas construídas pelos professores apresentam características próprias e que podem complementar a pesquisa produzida na universidade. Para ampliar o conhecimento sobre o tema, Stenhouse (1991) e Elliott (2000) defendem a colaboração entre o professor que pesquisa a sua própria prática pedagógica e o professor universitário, que tem na escola o seu objeto de investigação. Essa colaboração pode permitir conhecer um pouco mais sobre o processo de criação realizado pelo professor, além de contribuir para a divulgação do conhecimento por ele produzido. A parceria entre pesquisadores da escola e da universidade também é uma forma de estimular a valorização do conhecimento elaborado, respeitando as suas características próprias.

Foi com base nesses pressupostos que elaboramos este estudo, em colaboração com um professor que ensina EF na Educação Básica e que age como pesquisador. Interessava ao professor, assim como aos demais integrantes da equipe de pesquisa, identificar as percepções dos estudantes sobre as aulas que experimentaram, sob sua orientação. Este foi um dos objetivos que norteou a realização deste estudo. Para Stenhouse (1991), conhecer o olhar dos alunos sobre a aula é uma forma do professor obter informações sobre o seu próprio modo de ensinar.

A perspectiva discente sobre a EF tem sido analisada em inúmeros estudos, como os realizados por Darido (2004) e Brandolin et al. (2015). Em síntese, esses e outros estudos demonstram que as aulas são bastante apreciadas, principalmente por estudantes mais novos. Alunos associam as aulas de EF à prática de modalidades esportivas, algo que se repete durante toda a Educação Básica. Nos anos finais do Ensino Fundamental e durante o Ensino Médio, a participação nas aulas diminui, à medida em que aumenta a porcentagem de estudantes que consideram o componente pouco relevante (Darido, 2004). As percepções dos estudantes são, em grande parte, influenciadas pelas experiências que lhes foram proporcionadas durante suas aulas. Diferentemente da maioria dos estudos realizados, esta pesquisa busca identificar as percepções construídas, a partir de uma experiência específica, criada pelo professor colaborador.

O segundo objetivo deste estudo é discutir as percepções do próprio professor sobre as suas aulas e sobre as percepções apresentadas por seus alunos. Acreditamos que ouvir sensivelmente o professor e os estudantes permite-nos contribuir para explicitar os modos como ele, sendo pesquisador da própria prática, pode ter construído conhecimentos cotidianamente e como esses conhecimentos influenciam a concretização e a transformação das suas aulas.

\section{MÉTODO}

Para atingir os objetivos propostos, escolhemos realizar uma pesquisa colaborativa, considerada por Stenhouse $(1980 ; 1991)$ e Elliott (2000) uma estratégia que possibilita superar algumas barreiras que dificultam a realização de pesquisas por parte dos professores. Por influência desses e de outros autores, esta forma de investigar vem se tornando mais frequente na pesquisa educacional e, como explica Ibiapina (2016, p. 34), permite investigar "na ação e com os professores, em vez de se falar sobre eles".

Ibiapina (2016) explica que a colaboração entre aqueles que conduzem uma pesquisa pode acontecer de diferentes formas. Entretanto, a autora destaca que a essência desta forma de pesquisar está na participação conjunta de todos os envolvidos nas decisões sobre os rumos a serem seguidos na pesquisa. Partindo dessa 
perspectiva, na pesquisa que realizamos, o professorpesquisador - que aqui será ficticiamente identificado como Marcelo - participou ativamente nas decisões tomadas em cada etapa da pesquisa, colaborando na elaboração deste artigo, inclusive.

Quanto às características como professor, Marcelo trabalha há oito anos na educação básica, tendo realizado mestrado e doutorado, mantendo-se próximo à universidade. Como peculiaridade, o professor tem se preocupado em pesquisar e compartilhar os conhecimentos elaborados por meio da sua docência. Possui artigos e trabalhos apresentados em eventos científicos.

Além do professor, participaram da pesquisa 48 estudantes de uma escola da rede pública municipal da cidade de São Paulo, que cursavam o $9^{\circ}$ ano do Ensino Fundamental e foram alunos de Marcelo no período entre o $4^{\circ}$ e o $7^{\circ}$ anos. Com o consentimento de seus responsáveis e da diretora da unidade escolar, os estudantes aceitaram contribuir para a pesquisa, respondendo a um questionário e participando de entrevistas em grupo. Os procedimentos adotados foram aprovados por Comitê de Ética em Pesquisa, no parecer número 1.762.216.

Com a utilização do questionário, nossa intenção foi obter informações do maior número possível de estudantes, já que o professor desejava conhecer as percepções da maior parte de seus alunos. 0 questionário, construído pela própria equipe de pesquisa a partir das informações fornecidas por Marcelo, foi organizado em duas partes. Na primeira delas, os estudantes avaliaram a prática pedagógica do professor, a partir de quatro tópicos: as práticas corporais tematizadas, os espaços físicos utilizados, a metodologia de ensino implementada e os instrumentos de avaliação aplicados. Para analisar cada tópico, e de acordo com a descrição que Marcelo fez, foram apresentadas algumas opções que os estudantes poderiam selecionar, caso acreditassem que aquele tema, espaço, método ou instrumento de avaliação esteve presente nas aulas de Marcelo. Havia, também, um espaço para que eles pudessem acrescentar mais informações sobre cada um dos tópicos, se assim o desejassem.

A segunda parte do questionário foi composta por quatro questões abertas, nas quais os participantes deveriam apresentar suas percepções sobre o trabalho realizado pelo professor Marcelo, sobre os conhecimentos aprendidos nas aulas, sobre a importância da EF na escola e sobre os momentos que consideraram marcantes durante os quatro anos de contato com o professor. O questionário foi aplicado na própria escola, por três integrantes da equipe de pesquisa.
Para aprofundar e explicitar as percepções expressas no questionário, os estudantes foram convidados a participar de entrevistas em grupo. 25 deles aceitaram o convite e foram distribuídos em três grupos. As entrevistas foram conduzidas pelo próprio Marcelo, com a participação de outros três integrantes da equipe de pesquisa, que foram responsáveis pela observação e pelo registro, em áudio e vídeo, dos encontros realizados. Antes de iniciar as entrevistas, os estudantes tiveram a oportunidade de tomar contato com materiais produzidos por Marcelo. Adaptamos o método adotado por Venâncio (2014) edisponibilizamos algumas atividades e tarefas elaboradas pelos próprios estudantes, assim como fotografias produzidas durante o período em que Marcelo era professor deles.

O questionário e as entrevistas, após transcritas, passaram por uma análise temática de conteúdo, seguindo as proposições de Braun e Clarke (2006). Os resultados dessa análise foram apresentados e discutidos com Marcelo, durante uma entrevista semiestruturada. Naquele momento, ele pode apresentar suas percepções sobre as suas aulas e sobre a forma como elas são percebidas por seus alunos. Essa entrevista também foi analisada com a aplicação da análise temática de conteúdo.

\section{A PRÁTICA PEDAGÓGICA A PARTIR DAS PERCEPÇÕES DO PROFESSOR E DE SEUS ESTUDANTES}

Identificamos três temáticas recorrentes a partir das percepções do professor e dos estudantes sobre a prática pedagógica e as aulas. A seguir, detalhamos as "práticas corporais tematizadas", "a organização das aulas" e "os instrumentos de avaliação".

\section{PRÁTICAS CORPORAIS TEMATIZADAS}

Foi possível constatar que os estudantes mencionaram diferentes práticas corporais tematizadas durante as suas aulas. Destacamos alguns trechos de resposta dos estudantes para ilustrar suas declarações:

[...] Slakline, parkur, vôlei, basquete, futebol, skate, vôlei e basquete para pessoas com deficiência, assistimos filmes sobre danças (ballet e hip-hop), esgrima, boxe, judô, ginástica artística, rítmica e acrobática, entre outras. (Aluna 5 - questionário)

Diferentemente do que ocorreu nas entrevistas, no momento em que os questionários foram aplicados os estudantes não haviam ainda tomado contato com as imagens e atividades disponibilizadas, respondendo apenas com base em suas lembranças pessoais. Ainda assim, percebemos que alguns deles conseguiram 
resgatar na memória uma variedade de práticas corporais tematizadas. No quadro 1 apresentamos uma síntese de todas as atividades mencionadas.

Quadro 1. Práticas corporais percebidas pelos estudantes.

\begin{tabular}{|l|l|}
\hline Práticas Corporais & Modalidades tematizadas \\
\hline $\begin{array}{l}\text { Jogos e } \\
\text { brincadeiras }\end{array}$ & $\begin{array}{l}\text { Jogo de tabuleiro criado pelos alunos, } \\
\text { Bolinha de gude, Futebol de botão, } \\
\text { Barra manteiga, Queimada, Jogo da } \\
\text { velha humano, Xadrez. }\end{array}$ \\
\hline Ginástica & Rítmica, Artística, Acrobática e Geral. \\
\hline Luta & $\begin{array}{l}\text { Judô, Esgrima, Capoeira, Boxe, Sumo, } \\
\text { Jogos de Luta (braço de ferro e cabo } \\
\text { de guerra). }\end{array}$ \\
\hline Dança & $\begin{array}{l}\text { Frevo, Forró, Chula, Samba, Xaxado, } \\
\text { Axé, Funk. }\end{array}$ \\
\hline Esporte & Vôlei, Basquete, Futebol. \\
\hline Esportes Radicais & $\begin{array}{l}\text { Slackline, Bicicleta, Skate, Patins, } \\
\text { Rapel, Arvorismo, Tirolesa, Parkour. }\end{array}$ \\
\hline $\begin{array}{l}\text { Esportes } \\
\text { Adaptados }\end{array}$ & $\begin{array}{l}\text { Goalball, Futebol para deficientes visuais, } \\
\text { Corrida vendado, Vôlei sentado, Esgrima } \\
\text { sentado, Basquete para deficientes. }\end{array}$ \\
\hline
\end{tabular}

Fonte: dados da pesquisa.

Chama-nos a atenção o fato de muitos comentários dos estudantes constarem nos questionários sobre os esportes adaptados em suas aulas. Quando questionados sobre os momentos mais marcantes de suas aulas, dez estudantes destacam as atividades realizadas e as discussões sobre a inclusão da pessoa com deficiência na EF e no esporte, como o aluno 17:

Eu aprendi que não importa se a pessoa é deficiente ou não é. O que realmente importa é ver que todos podem praticar diversas modalidades. (Aluna 17 - questionário)

Ao tomar contato com as respostas apresentadas por seus alunos, Marcelo demonstrou certa surpresa. Ele esperava que os estudantes se lembrassem de diversas práticas corporais apresentadas nas aulas. Mas imaginava que esse indício apareceria apenas durante as entrevistas. Ele afirma

[...] eu não tinha noção do que mais marcou para eles porque, por exemplo, quando eu perguntava "O que você aprendeu no ano?", era naquele ano o que eles tinham apreendido e naquele papel. Agora, depois que você vai embora, você não sabe o que os alunos lembram. (Marcelo - entrevista)

A diversificação dos temas estudados nas aulas de EF tem sido defendida por diversos autores, como Betti
(2011) e Bracht (2011). Embora todos eles defendam posições epistemológicas diferentes sobre as formas de organizar as ações didáticas do componente curricular, é consenso que o desenvolvimento de diferentes práticas corporais nas aulas é um grande desafio para os professores que trabalham na escola. A partir do olhar dos estudantes, é possível inferir que essa diversificação aconteceu nas aulas de Marcelo.

Venâncio (2014) e Guarinon (2016) descreveram em seus estudos que estudantes de escolas estaduais e municipais de São Paulo mencionaram ter vivenciado diversificadas práticas corporais durante as aulas de $E F$, se aproximando da representação que os discentes do professor Marcelo construíram durante as aulas por ele conduzidas. Além disso, Venâncio (2017) aponta que as relações dos estudantes com os saberes elaborados, a partir das aulas, implica em experiências que perduram ao longo da vida.

\section{A ORGANIZAÇÃO DAS AULAS}

É possível perceber, a partir da resposta ao questionário pelos estudantes, que o professor também diversifica os espaços nos quais essas práticas corporais têm sido tematizadas. No questionário, diante de uma lista com sete locais diferentes, os discentes deveriam assinalar aqueles que foram utilizados durante as aulas de Marcelo. Os resultados obtidos são apresentados na figura 1.

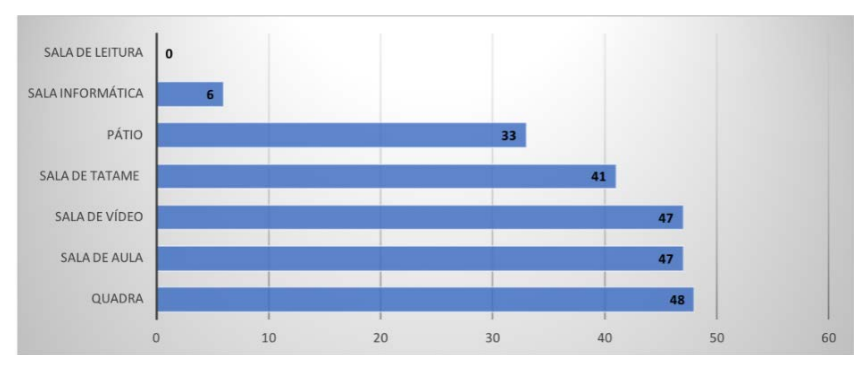

Figura 1. Percepções dos estudantes sobre os espaços utilizados. Fonte: dados da pesquisa

Quadra, sala de aula e sala de vídeo foram os espaços indicados com maior frequência. Marcelo explica que não foram realizadas aulas de EF na sala de leitura, evidenciando que os estudantes foram coerentes ao não assinalar aquele espaço, quando responderam os questionários. A sala de tatame e o pátio também foram espaços selecionados por um grande número de alunos. Alguns estudantes não apenas mencionaram o espaço utilizado, mas detalharam as atividades realizadas em cada local:

No pátio foi um futebol de cegos e usou o pátio para fazer esgrima entre outras coisas. (Aluno 14 questionário) 
Bem, foram utilizados muitos lugares, mas o lugar que eu mais penso quando relembro das aulas é a sala de vídeo, pois fazíamos bastante discussões lá. (Aluno 16 - questionário)

Durante as entrevista, os alunos confirmaram os espaços identificados no questionário e ainda acrescentaram outros:

Teve aula até aqui fora! Como é o nome?... No jardim! (Aluno 11 - entrevista)

Sala de artes, Sala de informática! (Aluno 14 . entrevista)

Chama-nos a atenção o fato de apenas seis estudantes assinalarem a utilização da sala de informática. Em sua entrevista, Marcelo explicou que esse espaço foi utilizado para estimular a realização de pesquisas sobre temas da EF. Contudo, naquele momento as aulas foram aplicadas por outro professor, responsável pela sala de informática. Talvez por isso os estudantes não tenham associado o espaço com as aulas de EF.

Diante desses resultados, acreditamos que o professor Marcelo aproveitou diversos espaços durante a realização das suas aulas. Ao tematizar diversificadas manifestações da cultura corporal com os estudantes, o docente precisou utilizar diferentes locais da escola para alcançar os seus objetivos educacionais. Para González e Fraga (2012), realizar registros sobre os temas que foram desenvolvidos ou estimular apresentações de seminários em sala de aula, leva os estudantes a refletir sobre os conteúdos aprendidos. Os autores também apontam que realizar pesquisas na sala de informática, ou mesmo fora do espaço escolar com os familiares, é de extrema importância para que os discentes possam compreender de forma ampla os conhecimentos sobre as práticas corporais.

Além de propostas, podemos identificar na literatura especializada relatos de experiência de professores que estão utilizando diferentes espaços da escola para que alunos reflitam de forma sistematizada sobre os temas estudados. Bocchini (2017) tematizou o samba, realizando a leitura de textos com os alunos em sala de aula, a apreciação de documentários na sala de vídeo e apresentações de samba no pátio da escola. Já Filgueiras e Pacheco (2017) descreveram uma experiência em que um professor estimulou a reflexão sobre o tema "Padrões de beleza, saúde e publicidade", em diferentes locais da escola e propôs que os estudantes entrevistassem os seus familiares sobre essa temática, realizando um trabalho interdisciplinar.
Portanto, para que o docente possa desenvolver diferentes conteúdos sobre as práticas corporais que são tematizadas na EF é necessário que não se restrinja à utilização da quadra em suas aulas. Nesse sentido, os estudantes de Marcelo recordaram-se dos muitos espaços utilizados nas aulas que tiveram com ele, apontando a importância de diversificar os locais existentes na escola para pensar em diferentes atividades de ensino.

Em outra parte do questionário, os alunos poderiam selecionar, na lista previamente apresentada, as atividades de ensino que se lembram de ter vivenciado durante suas aulas. Tinham também a opção de acrescentar outras atividades, se assim o desejassem. Os resultados obtidos são apresentados no quadro 2 .

Quadro 2. Percepções dos estudantes sobre as atividades de ensino utilizadas.

\begin{tabular}{|c|c|}
\hline $\begin{array}{l}\text { Estr } \\
\text { Ensi }\end{array}$ & Relato dos Estudantes \\
\hline Aulas prática & $\begin{array}{l}\text { As aulas na quadra eram as melhores. } \\
\text { (Aluno } 24 \text { - questionário) }\end{array}$ \\
\hline $\begin{array}{l}\text { Utilização de } \\
\text { filmes }\end{array}$ & $\begin{array}{l}\text { [...] estrada para glória. É isso né? Que tinha } \\
\text { preconceito racial entre os jogadores de } \\
\text { basquete. (Aluno } 12 \text { - entrevista) } \\
\text { [...] do filme dos lanches do Mac Donald's. } \\
\text { Começou a ter problemas de saúde. } \\
\text { (Aluno } 23 \text { - entrevista) }\end{array}$ \\
\hline Aulas & $\begin{array}{l}\text { Na sala de aula nós aprendíamos coisas } \\
\text { diferentes. (Aluno } 5 \text { - entrevista) } \\
\text { [...] o lugar que eu mais penso quando } \\
\text { relembro das aulas é a sala de vídeo, pois } \\
\text { fazíamos bastante discussões lá. (Aluno } 7 \\
\text { - entrevista) }\end{array}$ \\
\hline $\begin{array}{l}\text { lização de } \\
\text { tos }\end{array}$ & $\begin{array}{l}\text { Ah é!(lembro) da reportagem sobre } \\
\text { ginástica. (Aluno 4- entrevista) }\end{array}$ \\
\hline $\begin{array}{l}\text { Convite a } \\
\text { especialistas }\end{array}$ & $\begin{array}{l}\text { Trazia especialistas. Eu lembro que ele } \\
\text { trouxe um cara do judô ...(Aluno } 36 \text { - } \\
\text { questionário) }\end{array}$ \\
\hline $\begin{array}{l}\text { Realização de } \\
\text { passeios ou } \\
\text { visitas }\end{array}$ & $\begin{array}{l}\text { O museu do futebol eu fui. Eu tinha visto } \\
\text { a história lá de quando começou e várias } \\
\text { chuteiras diferentes. (Aluno } 2 \text { - entrevista) } \\
\text { Vocês lembram do dia da ETEC? Que } \\
\text { temos que escalar o negócio! (Aluno } 13 \\
\text { - entrevista) }\end{array}$ \\
\hline $\begin{array}{l}\text { Vídeos do } \\
\text { youtube }\end{array}$ & $\begin{array}{l}\text { Também a gente assistia a muitos vídeos } \\
\text { em algumas aulas (Aluno } 2 \text { - questionário) } \\
\text { [...] nas aulas de vídeo era sempre } \\
\text { mostrado como o esporte era realmente. } \\
\text { (Aluno } 14 \text { - questionário) }\end{array}$ \\
\hline
\end{tabular}

Fonte: dados da pesquisa. 
As atividades de ensino mais citadas foram as aulas práticas, assinaladas por $92 \%$ dos estudantes, seguidas pela utilização de filmes e de aulas teóricas, com $83 \%$ e $67 \%$, respectivamente. O uso de textos (65\%), a participação de convidados com conhecimentos especializados sobre determinados temas $(62, \%)$, a realização de passeios ou visitas (60\%) e o acesso a vídeos do Youtube $(42 \%)$ também foram atividades assinaladas por grande parte dos estudantes, evidenciando a variedade de formas de ensino utilizadas pelo professor. Alguns alunos também detalharam, nos questionários e durante as entrevistas, as formas como essas atividades foram utilizadas, como é possível perceber de seus relatos, destacados na figura 3. Assim, eles apontam as visitas ao Museu do Futebol e a uma Escola Técnica especializada na formação de profissionais de nível técnico para trabalhar com o Esporte. Eles também ressaltaram a presença de especialistas que apresentaram práticas como judô, capoeira e jiu-jitsu.

Em sua entrevista, Marcelo confirmou e exemplificou a utilização dessas estratégias. Sobre o uso de textos nas aulas, ele afirma:

[...] eu trouxe uma reportagem que discutia quais eram os sintomas da anorexia e sempre aparecia, principalmente, uma menina com aqueles sintomas de anorexia e bulimia. (Marcelo - entrevista)

Em outro momento, ele explicou sua intenção ao trazer convidados que contribuíram para a análise de algumas práticas corporais, especialmente ao tratar as lutas:

[...] trazer o professor é importante porque foi uma questão de diminuir a resistência. Muitos alunos faziam judô e esse professor era muito respeitado na comunidade. Eles (os alunos) resistiam à minha aula e, quando veio o professor [...], os alunos que faziam judô se destacaram. Então, esses alunos inverteram o jogo, nesse momento, porque eles eram os mais importantes. (Marcelo - entrevista)

Estudos demonstram que, assim como Marcelo, há outros professores que valorizam a construção de aulas com atividades variadas. Vieira et al. (2015), por exemplo, identificaram professores que têm utilizado textos escritos durante suas aulas. Maldonado et al. (2017) encontraram docentes que relatam a utilização de seminários, planejamento participativo, organização de torneios esportivos pelos estudantes, feiras, debates, mapeamentos, mapa conceitual e práticas interdisciplinares.

Acreditamos que diversificar as atividades de ensino durante as aulas é uma ação didática de extrema relevância para que os conteúdos que são tematizados pelos docentes realmente tenham sentido e significado para os estudantes.

\section{OS INSTRUMENTOS DE AVALIAÇÃO}

Os alunos identificaram diferentes instrumentos de avaliação utilizados pelo professor. Provas, participação nas aulas, elaboração de charges e de jogos e análise de filmes foram os instrumentos selecionados com mais frequência, como apresentado na figura 2.

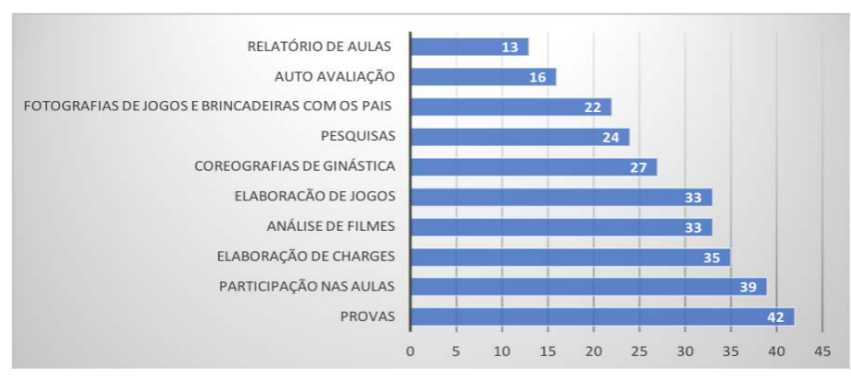

Figura 2. Instrumentos de avaliação percebidos pelos estudantes. Fonte: dados da pesquisa

Em sua entrevista, Marcelo analisou alguns dos instrumentos de avaliação que utilizou com esses estudantes. Com relação aos relatórios, ele afirmou não utilizar esse instrumento com frequência. Mas, a menção dos estudantes pode refletir as escolhas feitas, quando iniciou seu trabalho com a turma, como podemos perceber no trecho da entrevista, destacado a seguir:

[...] quando eu entrei na turma eles resistiram, obviamente, porque eles não faziam nada. Algumas crianças não queriam fazer aula e uma das estratégias era pedir o relatório de aula. (Marcelo - entrevista)

A partir dos relatos dos estudantes e do professor, é possível perceber que diferentes instrumentos foram utilizados por Marcelo, como forma de avaliação nas aulas. Mas, ele enfatiza que os instrumentos de avaliação são, também, estratégias didáticas:

[...] eu acho que a charge é uma estratégia didática. A análise do filme é uma estratégia didática, embora ela também seja um instrumento de avaliação. A elaboração de jogos, a coreografia de ginástica é uma estratégia didática. (Marcelo - entrevista)

Sendo assim, o professor defende que os alunos tenham diferentes oportunidades nas aulas, ou seja, não só trabalhar com esportes que envolvam um aspecto técnico e tático, mas também vivenciar lutas, ginástica, dança, atividades que envolvam aspectos atitudinais, em que eles possam utilizar sua criatividade na elaboração dessas atividades. 
Outros estudos também apontam uma mudança paradigmática nas práticas avaliativas de muitos docentes de EF escolar. Autores comoSantos, Maximiano e Frossard (2016) e Oliveira e Venâncio (2017), descreveram experiências nas quais os professores têm utilizado instrumentos diversificados de avaliação para compreender os conteúdos que os estudantes aprenderam e repensar as suas ações didáticas.

A partir das percepções apresentadas pelos estudantes, é possível conhecer algumas características da prática pedagógica implementada por Marcelo. A menção à utilização de textos e vídeos, assim como a realização de avaliações diversificadas, evidencia que ele não se preocupa apenas em criar momentos para que seus alunos vivenciem diferentes práticas corporais, mas para que eles se apropriem criticamente delas, identificando suas características, suas possibilidades e alguns caminhos para sua transformação. As intenções do professor são percebidas por seus alunos, uma vez que eles relatam, em seus questionários, ter aprendido conhecimentos relacionados às diferentes dimensões dos conteúdos, exemplificados no quadro 3.

Quadro 3. Dimensões dos conteúdos na aprendizagem.

\begin{tabular}{|l|l|}
\hline $\begin{array}{l}\text { Dimensões } \\
\text { dos Conteúdos }\end{array}$ & \multicolumn{1}{c|}{ Relatos dos Estudantes } \\
\hline Conceitual & $\begin{array}{l}\text { Aprendemos muito sobre o corpo humano, } \\
\text { dos músculos, dos ossos, etc. (Aluna 33) } \\
\text { (Aprendi) a função do músculo, dos ossos; } \\
\text { diferentes danças de várias etnias. (Aluno 9) }\end{array}$ \\
\hline Procedimental & $\begin{array}{l}\text { (Aprendemos) a se defender e a controlar } \\
\text { nossos batimentos; como jogar, brincar e } \\
\text { como fazer cada tipo de esporte. (Aluno 42) } \\
\text { Aprendi um pouco de cada esporte de como } \\
\text { e quais pessoas praticam. Aprendi também } \\
\text { que esporte é para todos. (Aluno 14) }\end{array}$ \\
\hline Atitudinal & $\begin{array}{l}\text { Que todos podem fazer esporte e que as } \\
\text { vezes a pessoa aparenta ter saúde e não tem. } \\
\text { Por exemplo, um magro aparenta ter saúde, } \\
\text { praticando esporte. Mas ele usa anabolizantes } \\
\text { ou sofre de distúrbios. (Aluno 7) } \\
\text { A respeitar, trabalhar em equipe, o que } \\
\text { é crítica, padrão de beleza, preconceito. } \\
\text { (Aluno 26 ) }\end{array}$ \\
\hline
\end{tabular}

Fonte: dados da pesquisa.

Durante a entrevista, Marcelo apresenta seu olhar sobre o ensino de conteúdos, em uma das diferentes dimensões:

[...] meu principal foco é sempre trabalhar com questões atitudinais. Eu esperava mais questões conceituais aparecendo. Mas, eu tenho como foco na aula de EF trazer as questões conceituais e atitudinais. Eu penso que é mais importante para um cidadão olhar para as práticas corporais, entendendo essa prática, compreendendo, do que vivenciando ela. Mas, obviamente que tem questões procedimentais/ motoras que são importantes. (Marcelo - entrevista)

Esses resultados indicam que a prática pedagógica construída por Marcelo se reflete nos significados que seus alunos atribuem à EF. É inegável que eles apresentam um olhar diferente daquele descrito em grande parte dos estudos sobre a percepção discente, principalmente quando esses estudantes avaliam a relevância do componente curricular.

\section{O PROCESSO DE ELABORAÇÃO DO CONHECIMENTO PELO PROFESSOR E SUAS IMPLICAÇÕES}

Com base nos estudos de Stenhouse $(1980,1991)$ e Elliott (2000) - assim como em Fagundes (2016) e Cunha e Prado (2007), que se inspiram nos primeiros - é possível identificar algumas características do professor que age como pesquisador. A constante autoanálise é uma delas. A partir dessa autoanálise, o professor sistematiza a sua pesquisa, ou seja, identifica os aspectos relevantes de sua prática pedagógica que necessitam ser analisados, questionados e transformados; constrói hipóteses que orientam os caminhos de sua pesquisa; busca informações, elabora registros e dialoga com o conhecimento produzido e com seus pares. Nesse processo, ele transforma a sua prática pedagógica e, por fim, dá publicidade ao conhecimento produzido com outros professores.

Além dessas características, destacamos que o professor-pesquisador precisa ter discernimento para "não reinventar constantemente a roda", como alerta Elliott (2012). Nesse sentido, a teorização que cada professor realiza, a partir do contexto de sua própria prática pedagógica tem potencial inovador, à medida que busca o respaldo de seus pares para reelaborar criteriosamente os pressupostos teóricometodológicos de suas ações e reflexões. De acordo com Sanches Neto (2014), essa condição implica em compartilhar todo o processo de elaboração de saberes que culmina na publicização tanto da atividade de ensino quanto a de pesquisa, de modo indissociável, contribuindo para romper com o individualismo das práticas e potencializando o trabalho realizado em colaboração.

Assim, ao ouvirmos os estudantes e ao dialogarmos com o professor, foi possível identificar a presença dessas características em Marcelo, como exemplificamos no quadro 4. 
Quadro 4. Características do professor-pesquisador.

\begin{tabular}{|c|c|c|}
\hline \multicolumn{2}{|c|}{ A pesquisa do Professor } & Relatos do professor \\
\hline \multirow{2}{*}{\multicolumn{2}{|c|}{ Autoanalisa }} & $\begin{array}{l}\text { Sem sombra de dúvidas... teve muita resistência, e até hoje eu tenho certeza que eu utilizei estratégias } \\
\text { que eu não utilizaria, porque na verdade essa foi a minha primeira escola praticamente né. }\end{array}$ \\
\hline & & $\begin{array}{l}\text { Eu tinha a expectativa que eles conseguissem olhar para as práticas corporais enquanto as pessoas } \\
\text { que conseguem fazer uma reflexão mais aprofundada de uma forma mais crítica. Não sei se eu } \\
\text { consegui fazer isso. }\end{array}$ \\
\hline \multirow{5}{*}{ Sistematiza } & Questiona & $\begin{array}{l}\text { [...]eu percebi que, naquele momento, os alunos não respondiam pela escrita. Então, foi uma coisa } \\
\text { assim...empírica, eles não conseguem responder para mim com escrita. Então, eu vou tentar de } \\
\text { outra forma. Este até depois foi um dos temas que eu comecei a estudar mais. }\end{array}$ \\
\hline & $\begin{array}{l}\text { Formula } \\
\text { hipóteses }\end{array}$ & $\begin{array}{l}\text { [...] pode ser que eu não tenha conseguido chegar em um nível de aprofundamento das aulas que } \\
\text { fizesse com que eles lembrassem de questões conceituais. }\end{array}$ \\
\hline & \multirow[b]{2}{*}{ Dialoga } & [...] eu conheço muitas pesquisas que professores relatando aquilo que eles fizeram que sai do comum. \\
\hline & & $\begin{array}{l}\text { Eu tive um colega, nesse momento também. Era um professor da escola, que conhecia muitos } \\
\text { esportes radicais. Então, ele conhecia as técnicas e ficou comigo. Então, isso foi importante para } \\
\text { fazer, por exemplo, o Slakline. }\end{array}$ \\
\hline & Registra & $\begin{array}{l}\text { [...] como eu tenho tudo registrado hoje eu consigo. Eu converso com vários professores que têm uma } \\
\text { prática pedagógica interessante, mas não têm registro. E o registro não veio da minha formação inicial. } \\
\text { A formação inicial não discutiu registro. Ele veio da minha formação continuada. }\end{array}$ \\
\hline \multirow{2}{*}{\multicolumn{2}{|c|}{ Transforma }} & $\begin{array}{l}\text { Com eles, eu acho que só fiz isso mesmo. Mas, depois eu comecei a fazer judô para deficiente } \\
\text { visual também. Comecei a fazer atletismo para pessoas com deficiência. }\end{array}$ \\
\hline & & $\begin{array}{l}\text { [...] a única coisa eles tinham que fazer para mim era ter elementos de todas as ginásticas. Então, } \\
\text { ter elemento da ginástica artística, rítmica e acrobática. Assim, a gente criava uma coreografia de } \\
\text { ginástica geral. Hoje não. Hoje eu já peço para eles colocarem elemento de algum marcador social: } \\
\text { preconceito racial, questão de gênero ou questão de classe para compor essa coreografia. }\end{array}$ \\
\hline \multirow{2}{*}{\multicolumn{2}{|c|}{ Compartilha }} & [...] nesse momento, que já foi quase $2014-2015$, eu já escrevia sobre a minha própria prática. \\
\hline & & $\begin{array}{l}\text { Escrever sobre a prática pedagógica foi muito importante no processo, também, porque essa } \\
\text { escrita me fez pensar várias vezes. }\end{array}$ \\
\hline
\end{tabular}

Fonte: dados da pesquisa.

A partir da análise de Marcelo, podemos perceber que ele tem produzido conhecimento sobre as características de seus alunos e argumenta que, no passado, não havia essa mesma percepção. Ele também produz conhecimento sobre as próprias características e suas transformações, de modo reflexivo. Ainda, Marcelo produz conhecimentos sobre a sua prática pedagógica, propondo novos temas para as suas aulas, construindo novas atividades de ensino e reformulando os critérios e instrumentos de avaliação.

\section{CONSIDERAÇÕES FINAIS}

Consideramos que a identificação das percepções dos estudantes sobre as aulas de EF é um indício que possibilita o redimensionamento do trabalho de professores preocupados em pesquisar a própria prática pedagógica. Nesta pesquisa, esse indício foi efetivamente utilizado pelo professor. Ademais, consideramos que o processo reflexivo do professor sobre as suas aulas e sobre as percepções dos alunos transformou a perspectiva que tinha sobre si, ao confrontar a sua percepção baseada nas expectativas anteriores à pesquisa.
Ressaltamos que estudos sobre as percepções dos estudantes devem considerar a prática pedagógica vivenciada para analisar se e como essa prática se reflete nas representações dos estudantes sobre a EF. Por isso, sugerimos como perspectiva de pesquisa, a realização de estudos colaborativos que acompanhem o professor em suas aulas para olhar conjuntamente como essa pesquisa acontece durante a intervenção, o que pode ser concretizado por meio de estudos de caso e da pesquisa-ação.

\section{REFERÊNCIAS BIBLIOGRÁFICAS}

Betti M. O que se ensina e o que pode ser ensinado. A pedagogização dos conteúdos da Educação Física: tradição e renovação. Salto para o Futuro 2011;21(12):21-28.

Bins GN, Molina Neto V. Mojuodara: uma possibilidade de trabalho com as questões étnico-raciais na educação física. Rev Bras Ciênc Esporte 2017;39(3):247-253.

Bocchini D. Do batuque à identidade nacional: o samba na Educação Física Escolar. In: Farias US, Nogueira VA, Maldonado DT, editor. Práticas Pedagógicas Inovadoras nas aulas de Educação Física Escolar: indícios de mudanças. Curitiba: CRV, 2017. p. 171-182. 
Bracht V. Dilemas no cotidiano da Educação Física escolar: entre o desinvestimento e a inovação pedagógica. Salto para o Futuro 2011;21(12):14-20.

Brandolin F, Koslinsk MC, Soares AJG. A percepção dos alunos sobre as aulas de Educação Física no Ensino Médio. Rev Educ Fis/UEM 2015;26(4):601-610.

Braun V, Clarke V. Using thematic analysis in psychology. Qualitative Research in Psychology 2006;3(2):77-101.

Cunha R B, Prado, GVT. A produção de conhecimento e saberes do/a professor/a-pesquisador/a. Educar 2007; 23(30):251-264.

Darido SC. A educação física na escola e o processo de formação dos não praticantes de atividade física. Rev Bras Educ Fís Esporte 2004;18(1): 61-80.

Elliott J. La investigación-accion en educación. 4ed. Madrid: Ediciones Morata, 2000.

Elliott J. Educational action research and the teacher. In: Anais... Encontro do PIBID. A importância da pesquisa no desenvolvimento profissional do docente da escola básica. Campinas-SP: Unicamp, maio 2012.

Fagundes TB. Os conceitos de professor pesquisador e professor reflexivo: perspectivas do trabalho docente. Rev Bras Educ 2016;21(65):281-298.

Farias US, Nogueira VA, Maldonado DT. Práticas Pedagógicas Inovadoras nas aulas de Educação Física Escolar: indícios de mudanças. Curitiba: CRV, 2017.

Filgueiras IP, Pacheco MS. Educação Física integrada à área de linguagens: inovações na prática pedagógica do Ensino Médio. In: Nogueira VA, Farias US, Maldonado DT, editor. Práticas Pedagógicas inovadoras nas aulas de Educação Física Escolar: indícios de mudanças 2. Curitiba: CRV, 2017. p. 179-190.

González FJ, Fraga AB. Afazares da Educação Física na escola: planejar, ensinar, partilhar. Erechim: Edelbra, 2012.

Guarinon PC. Representações sociais e os currículos da Educação Física: com a palavra os alunos. São Paulo: Faculdade de Educação Física da Universidade de São Paulo; 2016, Dissertação de Mestrado.

Ibiapina IMLM. Reflexões sobre a produção do campo teóricometodológico das pesquisas colaborativas: gênese e expansão. In: Ibiapina IMLM, Bandeira HMM, Araújo FAM, editor. Pesquisa colaborativa: multirreferenciais e práticas convergentes. Teresina, PI: EduFPI, 2016. p. 33-62.
Maldonado DT, Farias US, Meireles BF, Santos AR, Moreira VS, Nogueira VA, Freire ES. Perspectivas de mudança nas práticas pedagógicas da Educação Física Escolar: uma análise dos estudos publicados nos anais de eventos paulistas. Conexões: Educ. Fís. Esporte e Saúde. 2017;15(3):349-367.

Martins ABR, Freire ES. O envolvimento dos alunos nas aulas de educação física: um estudo de caso. Pensar a Prática 2013;16(3):619-955.

Okimura-Kerr T, Ulasowicz C, Venâncio L, Sanches Neto L, editor. Educação física no ensino fundamental I: perspectiva de sistematização dos blocos de conteúdos temáticos. Curitiba: CRV, 2017.

Oliveira LP, Venâncio L. Avaliação na Educação Física: experiências de um professor e uma professora com seus alunos e alunas. In: Venâncio L, Sanches Neto L, Okimura-kerr T, Ulasowicz C, editor. Educação física no ensino fundamental II: saberes e experiências educativas de professores(as)pesquisadores(as). Curitiba: CRV, 2017. p. 97-114.

Sanches Neto L. O processo de elaboração de saberes por professores-pesquisadores de educação física em uma comunidade colaborativa. Rio Claro-SP: IB-Unesp, 2014. Tese de Doutorado em Ciências da Motricidade.

Santos W, Maximiano FL, Frossard ML. Narrativas docentes sobre avaliação do ensino-aprendizagem: da formação inicial ao contexto de atuação profissional. Movimento 2016;22(3):739-752.

Stenhouse L. Curriculum Research and the Art of the Teacher. In: Stenhouse L, editor.. Authority, Education and Emancipation. Heineman Educational Books, London, 1980. p. 155-162

Stenhouse L. Investigación y desarrollodel curriculum. 3a ed. Madrid, Ediciones Morata, 1991.

Venâncio L. O que nós sabemos? Da relação com o saber com e na Educação Física em um processo educacionalescolar. Presidente Prudente-SP: FCT-Unesp, 2014.Tese de Doutorado em Educação.

Venâncio L. Narrative of experience from school physical education: the case of a Brazilian woman. In: Menja J, García-Valcárcel A, Peñalvo FJG, Del Pozo MM, editor. Search and research: teacher education for contemporary contexts. Salamanca: Aquilafuente, 2017. p. 419-427.

Vieira PBA, Freire ES, Rodrigues GM. O texto escrito como recurso didático nas aulas de Educação Física: perspectiva e experiência dos professores. Movimento 2015;21(4):929-944. 